\title{
Oxidation and Erosion-Oxidation Behavior of Steels
}

\author{
Stela Maria de Carvalho Fernandes, Olandir Vercino Correa, Lalgudi Venkataraman Ramanathan* \\ Instituto de Pesquisas Energéticas e Nucleares - IPEN, \\ Av. Prof. Lineu Prestes, 2242, Cidade Universitária, 05508-000 São Paulo - SP, Brazil
}

Received: March 26, 2007; Revised: February 26, 2008

\begin{abstract}
The high temperature oxidation and erosion-oxidation (E-O) behavior of steels AISI 1020, 304, 310, and 410 were determined. These steels were selected to evaluate the effect of chromium content on its E-O resistance. The oxidation behavior was determined in a thermogravimetric analyzer. A test rig in which a specimen assembly was rotated through a fluidized bed of erodent particles was used to determine the E-O behavior. Alumina powder $(200 \mu \mathrm{m})$ was used as the erodent. The E-O tests were carried out in the temperature range $25-600{ }^{\circ} \mathrm{C}$, with average particle impact velocities of 3.5 and $15 \mathrm{~ms}^{-1}$ and impact angle of $90^{\circ}$. The oxidation resistance of the steels increased with chromium content. The E-O behavior of the steels was determined as wastage. The E-O wastage of the steels exposed to particle impact at low velocity was low but increased with temperature above $300{ }^{\circ} \mathrm{C}$. The E-O wastage of the different steels exposed to particle impact at high velocity was quite similar. The wastage increased with increase in temperature above $500{ }^{\circ} \mathrm{C}$. The increases in $\mathrm{E}-\mathrm{O}$ wastage of the steels observed at temperatures above 300,400 or $500{ }^{\circ} \mathrm{C}$, depending on the steel, were due mainly to a transition in the dominant wastage process, from 'erosion' to 'erosion-oxidation'.
\end{abstract}

Keywords: oxidation, erosion, erosion-oxidation, wastage, steels

\section{Introduction}

A vast amount of information is available about the oxidation behavior of various metals and alloys at high temperatures. The erosion behavior of metallic materials and ceramics at room temperature has been also extensively studied ${ }^{1-3}$. Nevertheless, a number of questions regarding correlations between erosion properties and physical parameters of materials remain unanswered. Information available about the conjoint effect of erosion and oxidation at high temperatures is still limited ${ }^{4-6}$. The results of some of the erosion-oxidation (E-O) studies demonstrate that there is synergy between erosion and oxidation. This indicates that the degradation caused by E-O can be greater than the sum of degradation caused by erosion and oxidation processes operating separately ${ }^{7-9}$. Corrosion products have also been shown to inhibit erosion ${ }^{10}$. That is, the wastage rate under E-O conditions can be lower than that in the absence of oxidation. These contrary observations have generated much attention in recent years about E-O processes.

E-O interactions have been described in terms of regimes. Kang et al. proposed the existence of four regimes as a function of increasing temperature, based on E-O studies of pure metals ${ }^{11}$. These regimes were termed: a) erosion of metal, which predominated at low temperatures; b) oxidation affected erosion, where the oxide and the metal eroded; c) erosion-enhanced oxidation, during which more oxide formed as it was eroded and d) oxide erosion, where only the oxide eroded. Modifications to these regimes and other interpretations about the existence of a variety of other sub E-O regimes have been proposed $^{12,13}$. Definition of E-O regimes has varied significantly, both in the number of regimes that have been proposed as well as in the criteria for defining transitions ${ }^{5}$. Justifications for the various regimes have depended on the E-O conditions and experimental evidence put forth to support the transitions. This signifies that there is potentially a number of interaction regimes depending on the criteria used to define the transitions.

Procedures to select materials resistant to high temperature E-O degradation are presently not available. A variety of metals, compos- ites, cermets and ceramics are used in industrial applications where E-O conditions prevail. The metallic materials include readily available alloys such as mild steel, stainless steels, rare earth containing iron-chromium or iron-chromium-aluminum alloys and hard material coated alloys. The criteria often used to select alloys subject to E-O conditions are hardness, cost and availability.

This paper presents the high temperature oxidation and erosionoxidation behavior of a variety of readily available steels such as AISI 1020, 304, 310 and 410. The oxidation measurements were carried out in the temperature range $25-600{ }^{\circ} \mathrm{C}$. The E-O measurements were made in a test rig, also in the temperature range $25-600{ }^{\circ} \mathrm{C}$, using alumina particles as the erodent at impact velocities of 3.5 and $15 \mathrm{~ms}^{-1}$.

\section{Methods and Materials}

The chemical composition of the steels AISI 1020, 304, 310 and 410 , used in this investigation is shown in Table 1 . Specimens for the oxidation tests and the E-O tests were cut to size from steel sheets, cleaned and degreased ultrasonically in acetone. The oxidation measurements were carried out in a thermogravimetric analyzer in the temperature range $25-600{ }^{\circ} \mathrm{C}$ and plots of weight gain vs. time obtained.

A schematic diagram of the E-O test rig is shown in Figure 1. In this rig a specimen assembly was rotated through a fluidized bed of erodent particles. Alumina powder with particles in the size range 212-150 $\mu \mathrm{m}$ was used as the erodent. The fluidized bed of particles was obtained by pumping pre-heated air through a porous plate supporting a bed of erodent particles. Fluidization of the erodent particles was done within a furnace and the erodent impact velocity on the test specimens was controlled by a motor that rotated the specimen assembly.

The E-O test specimens were weighed and fixed with AISI 310 screws to the specimen holder in the E-O test rig. The 
Table 1. Chemical composition of the steels, determined by $\mathrm{X}$ ray fluorescence spectroscopy.

\begin{tabular}{rcccccccc}
\hline Steel & \multicolumn{9}{c}{ Elements wt. $(\%)$} \\
\cline { 2 - 9 } AISI & $\mathrm{Cr}$ & $\mathrm{Ni}$ & $\mathrm{Mo}$ & $\mathrm{Mn}$ & $\mathrm{Si}$ & $\mathrm{P}$ & $\mathrm{Cu}$ & $\mathrm{Fe}$ \\
\hline 1020 & - & - & - & 0.33 & - & - & - & Balance \\
410 & 11.5 & 0.18 & - & 0.14 & 0.5 & 0.4 & - & Balance \\
304 & 18.7 & 8.0 & 0.03 & 1.4 & 0.6 & 0.04 & 0.09 & Balance \\
310 & 24.1 & 19.1 & 0.07 & 1.7 & 0.5 & - & 0.01 & Balance \\
\hline
\end{tabular}

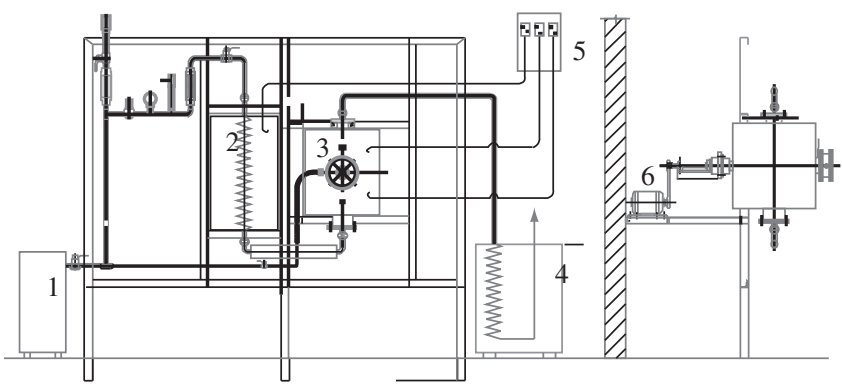

Figure 1. Schematic diagram of the erosion-oxidation test rig: 1) compressor; 2) pre-heating furnace; 3) E-O furnace; 4) system for retaining particles and for cooling; 5) control panel for controlling the motor and the furnaces; and 6) motor to rotate the specimens through the bed of erodent particles in the furnace.

specimens were positioned at the end of a crossed specimen holder. The E-O test conditions were: $25-600{ }^{\circ} \mathrm{C}$, average erodent impact velocities of 3.5 and $15 \mathrm{~ms}^{-1}$ and impact angle of $90^{\circ}$. After the tests, the specimens were weighed, examined in a scanning electron microscope, the surface reaction products analyzed by EDS and the surface hardness measured.

\section{Results and Discussion}

\subsection{Oxidation behavior}

The isothermal oxidation curves of the different steels at $500{ }^{\circ} \mathrm{C}$ and $600{ }^{\circ} \mathrm{C}$ are shown in Figure 2. At low temperatures, (R.T. $-400^{\circ} \mathrm{C}$ ) the oxidation weight gains of the different steels except AISI 1020 were very low. However at 500 and $600{ }^{\circ} \mathrm{C}$ the steels exhibited parabolic oxidation behavior after an initial transient stage. The parabolic rate constant of AISI 1020 was higher than that of the other alloys, which contained more than $12 \% \mathrm{Cr}$. Similar isothermal curves were also obtained at temperatures of $700,800,900$ and $1000{ }^{\circ} \mathrm{C}$. At these higher temperatures all the steels except AISI 1020 revealed parabolic oxidation behavior. The latter revealed an oxidation rate transition from parabolic to linear.

The higher oxidation rate of AISI 1020 was due primarily to the formation of $\mathrm{Fe}_{3} \mathrm{O}_{4}$. The scale formed on AISI 410 was a mixture of $\mathrm{Fe}_{3} \mathrm{O}_{4}$ and $\mathrm{Cr}_{2} \mathrm{O}_{3}$ on AISI 304 and 316 mainly $\mathrm{Cr}_{2} \mathrm{O}_{3}$. Overall, decrease in oxidation rates with increase in chromium content of the steel was clearly observed.

\subsection{Erosion-oxidation behavior}

The E-O behavior, expressed as wastage, of the four steels as a function of temperature is shown in Figures $3 \mathrm{a}$ and $3 \mathrm{~b}$. The steels were exposed to the E-O environment for 5 hours at 25, 100, 200, $300,400,500$ and $600{ }^{\circ} \mathrm{C}$. In Figure $3 \mathrm{a}$ it can be seen that wastage of the different steels was low up to $300{ }^{\circ} \mathrm{C}$. The wastage of AISI 1020 and AISI 410 increased above $300{ }^{\circ} \mathrm{C}$ and then decreased above $500{ }^{\circ} \mathrm{C}$. The wastage of AISI 304 was very low up to $400{ }^{\circ} \mathrm{C}$, and

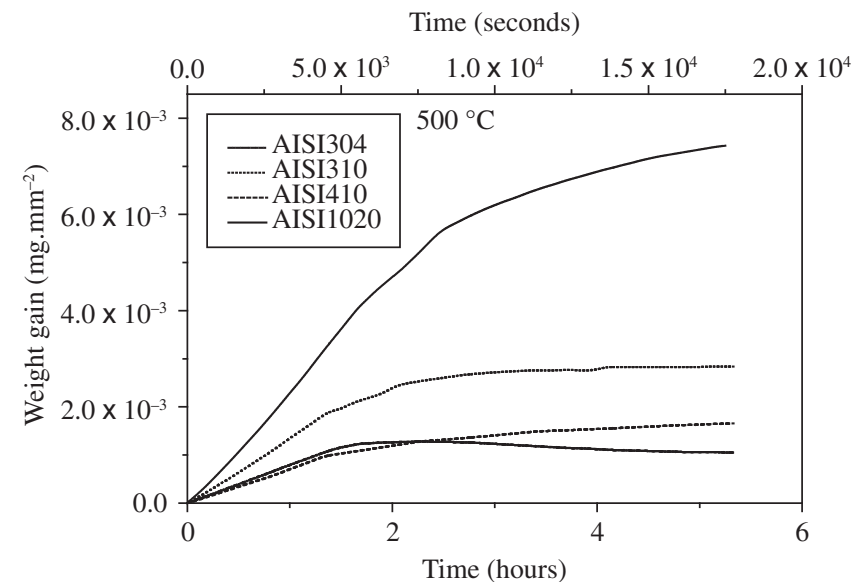

(a)

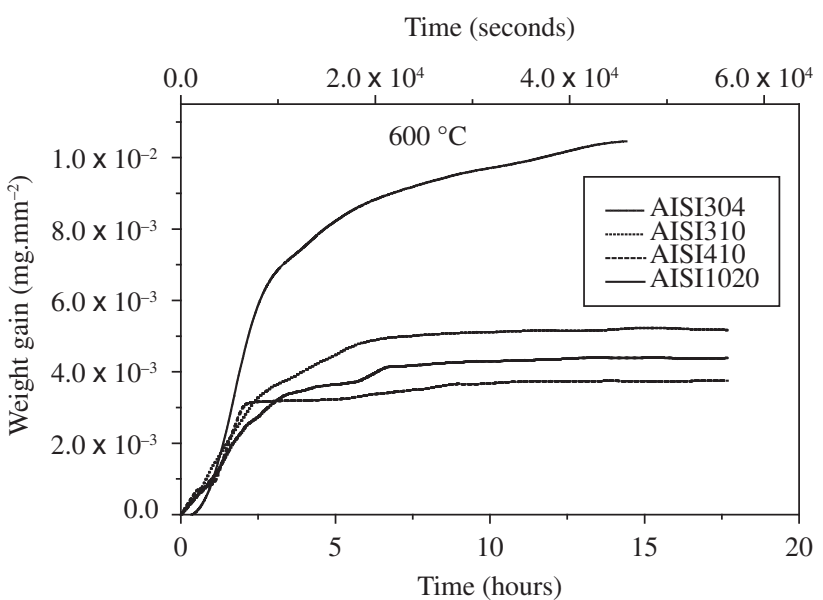

(b)

Figure 2. Isothermal oxidation behavior of the steels at: a) $500^{\circ} \mathrm{C}$ and b) $600{ }^{\circ} \mathrm{C}$.

it then increased. The wastage of AISI 310 remained quite low till $300{ }^{\circ} \mathrm{C}$ and then increased before decreasing again above $400{ }^{\circ} \mathrm{C}$. Overall variations in wastage with particle impact at low velocity is very low and is evident from the weight loss values on the y-axis of the graph. At high particle impact velocity, (Figure 3b), all steels revealed marked wastage at $100^{\circ} \mathrm{C}$ and this decreased with increase in temperature up to $500{ }^{\circ} \mathrm{C}$. The wastage of all the steels again increased with increase in temperature to $600{ }^{\circ} \mathrm{C}$. The wastage at $100{ }^{\circ} \mathrm{C}$ in this figure can be attributed to loss of air-formed surface oxide and base metal. With increase in temperature, the wastage decrease is due to formation of surface oxide. That is, the weight gain due to oxide formation is higher than loss of oxide due to particle erosion. At temperatures beyond $500{ }^{\circ} \mathrm{C}$ the net weight loss increases and is due to loss of the oxide as it is formed and loss of base metal. The oxide on AISI 1020 is mainly $\mathrm{Fe}_{2} \mathrm{O}_{3}$ at low temperatures and $\mathrm{FeO}$ at 


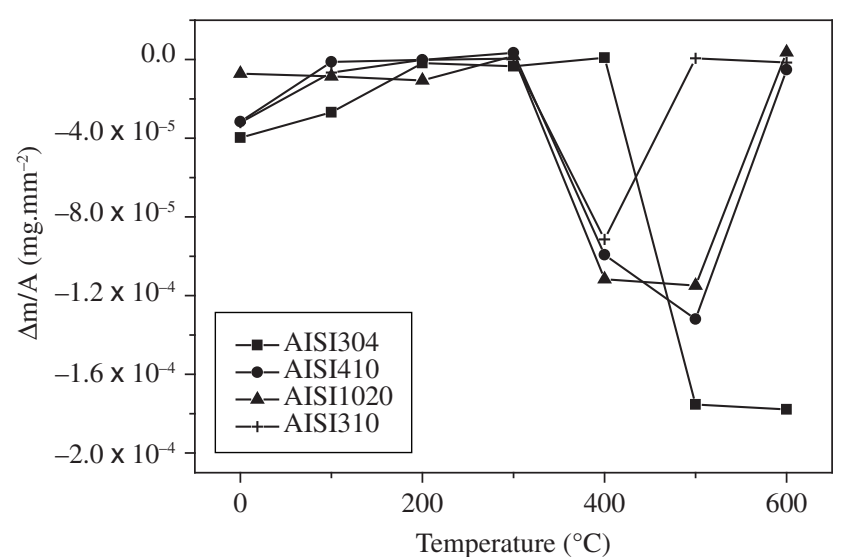

(a)

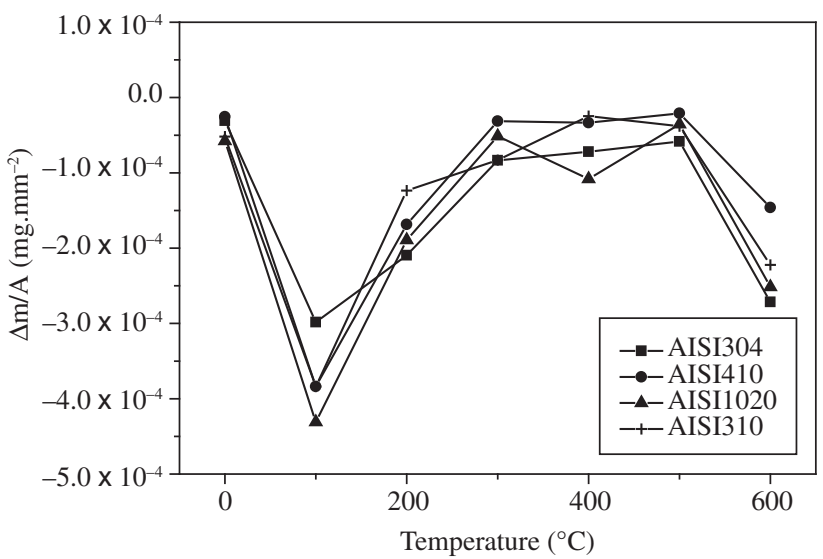

(b)

Figure 3. Wastage as a function of temperature of steels exposed for 5 hours in the E-O rig to: a) particle impact at low velocity; and b) particle impact at high velocity.

higher temperatures. The former is more ductile and therefore more resilient towards particle impact. On the other hand $\mathrm{FeO}$ is brittle and is easily removed. On the other $\mathrm{Cr}$ containing alloys, depending on the $\mathrm{Cr}$ content the surface oxide formed due to oxidation is a mix of iron and chromium oxides. In the initial stages the oxide formed is mainly iron oxide and subsequently it is $\mathrm{Cr}$ oxide. The outer Fe oxide is quickly removed by particle impact leaving behind the more resistant but thin layer of chromium dioxide close to the alloy interface. This accounts for the decreased wastage with increase in temperature up to $500{ }^{\circ} \mathrm{C}$. At temperatures above $600{ }^{\circ} \mathrm{C}$ the wastage increase could be attributed to removal of $\mathrm{Cr}$ oxide and the base metal.

Alumina inclusions were observed on the surfaces of many specimens following E-O exposure as shown in Figure 4. EDS spectra of these surfaces confirmed the presence of alumina particles. Some of the scatter in the data at low impact velocity in Figure 3 a could be related to weight increase associated with particle inclusion. This particle inclusion was observed on the surfaces of some steels, especially the austenitic steels.

To throw more light on the erosion-oxidation data obtained with particle impact at the two velocities, the hardness of the $\mathrm{Cr}$ containing steel specimens exposed for 5 hours at $500{ }^{\circ} \mathrm{C}$ to: a) no particles; b) particle impact at low velocity and c) particle impact at high velocity, were determined. The results are shown in Table 2.

Table 2 reveals that with particle impact the surface hardness of AISI 410 increases from 71 to 102 . Increase in particle impact veloc-
Table 2. Vickers microhardness of steel specimens exposed for 5 hours at $500{ }^{\circ} \mathrm{C}$ in the E-O rig to: a) no particles; b) particle impact at low velocity and c) particle impact at high velocity.

\begin{tabular}{cccc}
\hline \multirow{2}{*}{$\begin{array}{c}\text { Steels } \\
\text { (AISI) }\end{array}$} & \multicolumn{3}{c}{ Vickers microhardness $\left(\mathrm{g} . \mathrm{mm}^{-2}\right)$} \\
\cline { 2 - 4 } & $\begin{array}{c}\text { No particle } \\
\text { impact }\end{array}$ & $\begin{array}{c}\text { Particle impact } \\
\text { at low velocity }\end{array}$ & $\begin{array}{c}\text { Particle impact } \\
\text { at high velocity }\end{array}$ \\
\hline $410(12 \% \mathrm{Cr})$ & 71 & 102 & 103 \\
$304(18 \% \mathrm{Cr})$ & 72 & 72 & 72 \\
$310(25 \% \mathrm{Cr})$ & 92 & 82.5 & 95 \\
\hline
\end{tabular}

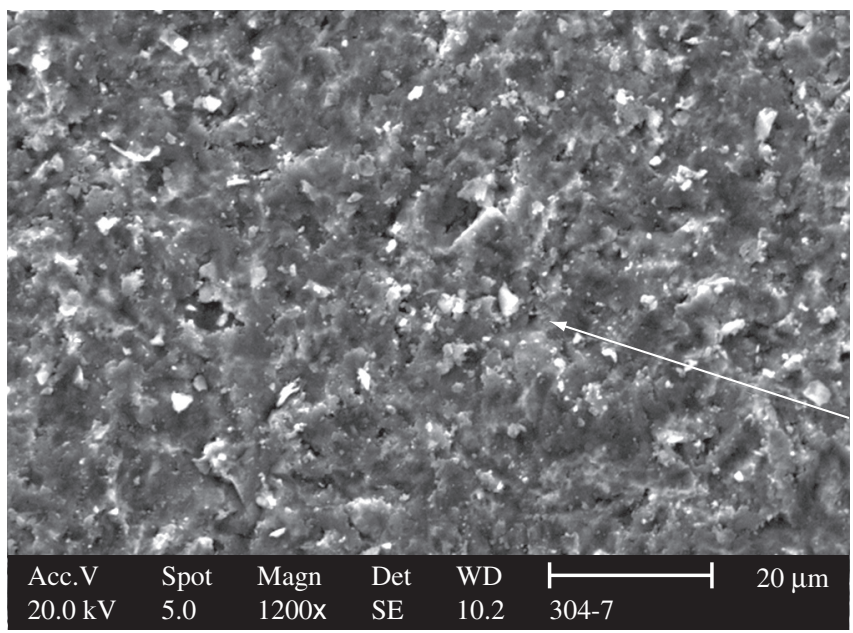

Figure 4. Scanning electron micrograph of the AISI 304 surface exposed to erodent particle impact at $15 \mathrm{~ms}^{-1}$ for 5 hours at $300{ }^{\circ} \mathrm{C}$. The surface reveals embedded alumina particles (arrow).

ity did not affect the surface hardness of this steel. This increase in hardness is due probably to a ductile to brittle transition in the steel, that normally takes place around $500{ }^{\circ} \mathrm{C}$. The $18 \% \mathrm{Cr}$ containing AISI 304 and the $25 \% \mathrm{Cr}$ containing AISI 310 did not show any significant change in hardness caused by particle impact.

\subsection{Wastage behavior of the steels}

At low temperatures, erosion of metal is the dominant process and wastage is said to be "erosion-dominated" "5,14,15. As the temperature increases, oxide formation increases. If the oxide is less erosion resistant than the underlying metal substrate, it is easily removed, together with the underlying metal, between successive erosive events, as the temperature is increased. Since the rate of oxidation increases rapidly with increase in temperature, this means that at a specific temperature, the wastage due to loss of oxide scale is greater than that due to loss of metal. This marks the transition to "erosion-corrosion dominated" behavior as observed in Figure 3 at temperatures above $300{ }^{\circ} \mathrm{C}$ for AISI 1020 and 410 and above $400{ }^{\circ} \mathrm{C}$ for AISI 304 and 316. If most or all the scale continues to be removed on particle impaction, the wastage rate increases, as the oxidation rate increases with temperature.

The composition of the steel influenced the composition of the scale and thus the erosion resistance. The ability to accommodate deformation and absorb impact energy at high temperature is a function of scale composition, with iron oxides more ductile than chromium oxides. The kinetics of scale growth is also dictated by alloy composition. Chromium dioxide forms on the high chromium containing alloys, and a transition to parabolic behavior occurs at 
high temperatures. On AISI 1020, at low temperatures, $\mathrm{Fe}_{3} \mathrm{O}_{4}$ scale forms and this protects to some extent. At higher temperatures, the scale formed is mainly $\mathrm{FeO}$ and this is not protective. The oxidation rate is very high and metal loss also high, compared with that at lower temperatures, where $\mathrm{FeO}$ scale does not form.

\section{Conclusions}

1. The oxidation rates of the steels varied with temperature and steel composition. AISI 1020 oxidized at high rates formed $\mathrm{Fe}_{3} \mathrm{O}_{4}$ scale. The oxides formed on AISI 410, 304 and 310 contained increasing amounts of $\mathrm{Cr}_{2} \mathrm{O}_{3}$;

2. The E-O wastage of AISI 1020 and 410 exposed to particles with low impact velocity was low up to $300{ }^{\circ} \mathrm{C}$ and thereafter increased with increase in temperature. The E-O wastage of AISI 304 under similar conditions also increased at temperatures beyond $400{ }^{\circ} \mathrm{C}$. However, the E-O wastage of the high Cr containing AISI 310 decreased to very low values;

3. The E-O wastage behavior of the different steels exposed to particle impact at high velocity was quite similar. The wastage increased with increase in temperature to $100{ }^{\circ} \mathrm{C}$ and thereafter decreased with increase in temperature to $500{ }^{\circ} \mathrm{C}$. At temperatures above $500{ }^{\circ} \mathrm{C}$ the wastage increased again; and

4. The increases in E-O wastage of the steels observed at temperatures around 300 and $400{ }^{\circ} \mathrm{C}$ upon exposure to particle impact at low velocity and above $500{ }^{\circ} \mathrm{C}$ upon exposure to particle impact at high velocity are due mainly to a transition in the dominant wastage process, from 'erosion' to 'erosionoxidation'.

\section{References}

1. Shewmon P, Sundararajan G. The erosion of metals. Annual Review of Materials Science. 1983; 13: 301-318.

2. Bitter JGA. A study of erosion phenomena, Part I. Wear. 1963; 6(1): $5-21$.
3. Hutchings IM, Winter RE. Particle erosion of ductile metals - mechanism of material removal. Wear. 1974; 27(1): 121-128.

4. Singh T, Sunderarajan G. The erosion behavior of 304 stainless steel at elevated temperatures. Metallurgical Transactions. 1990; 21A: 3187-3199.

5. Stack MM, Stott FH, Wood GC. Review of mechanisms of erosioncorrosion of alloys at elevated temperatures. Wear. 1993; 162-164(B): 706-712.

6. Stack MM, Bray L. Interpretations of wastage mechanisms of materials exposed to elevated temperature erosion-corrosion using erosion-corrosion maps and computer graphics. Wear. 1995; 186-187: 273-283.

7. Markworth AJ, Nagarajan V, Wright IG. An approach to modeling simultaneous high-temperature oxidation and erosion. Oxidation of Metals. 1991; 35(1-2): 89-106.

8. Levy AV, Zambelli G. Particulate erosion of NiO scales. Wear. 1981; 68(2): 305-331.

9. Tabakoff W. Experimental study on the effects of specimen sizes on erosion. Wear. 1983; 86(1): 65-72.

10. Stack MM, Lekatos S, Stott FH. Erosion-corrosion regimes: number, nomenclature and justification. Tribology International. 1995; 28(7): 445-451.

11. Kang CT, Pettit FS, Birks N. Mechanisms in the simultaneous erosionoxidation attack of nickel and cobalt at high temperatures. Metallurgical Transactions. 1987; 18A: 1785-1802.

12. Rishel DM, Pettit FS, Birks N. Some principle mechanisms in the simultaneous erosion and corrosion attack of metals at high temperatures. Materials Science and Engineering A. 1991; 143(1-2): 197-211.

13. Stephenson DJ, Nicholls JR. Modeling erosive wear. Corrosion Science. 1993, 35(5-8): 1015-1026.

14. Kunioshi CT, Correa OV, Ramanathan LV. Erosion-oxidation behavior of thermal sprayed $\mathrm{Ni20Cr}$ alloy and $\mathrm{WC}$ and $\mathrm{Cr}_{3} \mathrm{C}_{2}$ cermet coatings. Materials Research. 2005; 8(2):125-129.

15. Kunioshi CT, Correa OV, Ramanathan LV. High temperature oxidation and erosion-oxidation behaviour of HVOF sprayed Ni-20Cr, WC-20$\mathrm{Cr}-7 \mathrm{Ni}$ and $\mathrm{Cr}_{3} \mathrm{C}_{2}-\mathrm{Ni}-20 \mathrm{Cr}$ coatings. Surface Engineering. 2006; 22(2): 121-127. 